\title{
A experimentação na educação de jovens e adultos: uma prática significativa no processo de ensino aprendizagem
}

The experimentation of youth and adult education: a significant practice in teaching process learning

\author{
V. A. Bicho ${ }^{1 *}$; L. C. S. Queiroz ${ }^{1}$; G. C. Ramos ${ }^{2}$ \\ ${ }^{1}$ Curso de Ciências Naturais com Habilitação em Química, Universidade do Estado do Pará, 66113-010, Belém- \\ Pará,Brasil
}

${ }^{2}$ Departamento de Ciências Naturais, Universidade do Estado do Pará, 66113-010, Belém-Pará,Brasil

*valeriabicho_@hotmail.com

(Recebido em 08 de abril de 2016; aceito em 21 de abril de 2016)

\begin{abstract}
A pesquisa tem como objetivo investigar as dificuldades dos alunos da modalidade de Educação de Jovens e Adultos (EJA) no ensino de química bem como utilizar de práticas experimentais como ferramenta metodológica. $\mathrm{O}$ trabalho foi desenvolvido em uma turma de $4^{\circ}$ etapa da modalidade EJA em uma escola da rede pública municipal na cidade de São Miguel do Guamá localizada no estado do Pará. A pesquisa foi do tipo quali-quantitativa. No primeiro dia foi aplicado um questionário com o intuito de investigar quais as dificuldades dos alunos nas aulas de química, bem como, se o professor costumava realizar atividades experimentais. No segundo dia foi aplicada uma aula teórica sobre a História e Evolução dos Modelos Atômicos seguido de uma prática experimental, o Teste da Chama, e finalizado com a aplicação de um questionário a fim de verificar a contribuição das aulas práticas no ensino de química. Através dos resultados foi possível constatar que a maioria dos alunos investigados apresentavam dificuldades nas aulas de química e que as aulas experimentais contribuíram para uma melhor assimilação do conteúdo visto na teoria. Portanto, a utilização de atividades experimentais se mostrou de grande importância nas aulas de química na turma de EJA, pois favoreceu o processo de ensino aprendizagem.

Palavras-chave: Experimentação, Ensino de química, Aprendizagem
\end{abstract}

The research aims to investigate the difficulties of of youth and adult education (EJA) on chemistry teaching as well as use of experimental practices as a methodological tool. The work was developed in a group of $4^{\circ}$ stage of the EJA mode in a public school Hall in São Miguel do Guamá located in the State of Pará. The research was the qualitative quantitative type. On the first day it was applied a questionnaire in order to investigate what the difficulties of students in chemistry class and, if the teacher used to perform experimental activities. On the second day it was applied a theory lesson on the history and evolution of Atomic Models followed by an experimental practice, the flame Test, and finished with the application of a questionnaire to ascertain the contribution of practical classes in teaching chemistry. Through the results it was found that most students investigated presented difficulties in chemistry lessons and that experimental classes contributed to a better assimilation of the contents seen in theory. Therefore, the use of experimental activities proved to be of great importance in chemistry lessons in class of EJA because it favored the teaching learning process.

Keywords: Experimentation, Teaching chemistry, Learning.

\section{INTRODUÇÃO}

A Educação de Jovens e Adultos (EJA) é uma modalidade de ensino fundamental e médio que faz parte da educação básica no Brasil. Esta modalidade busca atender as pessoas que não tiveram acesso à educação na idade própria por diversos motivos. Os jovens e os adultos, são assegurados pela Constituição de 1988, onde o artigo 208 garante o dever do Estado com a educação básica e gratuita aqueles que não tiveram acesso na idade própria [1].

Esses adultos na maioria das vezes são trabalhadores, pais de família que deixaram o âmbito escolar muito cedo e apresentam outra realidade, pois trazem consigo experiências vividas no seu cotidiano que não podem ser desconsideradas. Para que a aprendizagem seja realmente 
concretizada, o ensino deve atender as necessidades e expectativas desses alunos que estão inseridos neste contexto escolar [3]. Para Nascimento [2], as estratégias organizadas pelo educador devem contemplar as necessidades daqueles que deixaram de frequentar a escola por alguma questão no decorrer de sua trajetória escolar.

Observa-se que ainda hoje há um grande número de adultos que ainda não concluíram o ensino fundamental, seja pela inserção muito cedo no mercado de trabalho, pela formação de família ou até mesmo pelo desestímulo que a educação de hoje tem proporcionado ao aluno, onde o mesmo é um puro armazenador de informações. Além do mais, a forma com que as metodologias tradicionais são aplicadas fazem com que o aluno ocupe o lugar de agente passivo no contexto educacional, não contribuindo com o envolvimento desses personagens na aquisição do conhecimento. Por isso novas práticas metodológicas estão sendo desenvolvidas a fim de estimular os estudantes, tornando-os seres ativos, motivados e interessados a buscar $\mathrm{o}$ conhecimento durante o processo educacional [4].

Essa posição de passividade do aluno no contexto educacional é um dos motivos que levam o estudante ao desinteresse nas aulas de química e ao fracasso no processo educacional.

Para tanto, o trabalho buscou através da experimentação, relacionar os conteúdos de química com o cotidiano dos alunos da EJA, possibilitando uma melhor compreensão do meio em que vive. Para Neto [3], o professor deve utilizar alguns recursos visando à melhor compreensão da disciplina de Química pelos alunos através da abordagem de temas interligados a situações de sua vivência.

Deste modo, este estudo teve como objetivo utilizar atividades experimentais nas aulas de química em uma turma de Educação de Jovens e Adultos como prática metodológica a fím de contemplar as necessidades existentes dos alunos desta modalidade. Segundo Santos; Freitas [5], "As aulas práticas na EJA proporcionam ao aluno melhor assimilação dos conteúdos, pois é uma possibilidade de o aluno aprender de forma objetiva e clara".

\section{MATERIAL E MÉTODOS}

Buscou-se abordar o conteúdo de Modelos Atômicos através de uma atividade experimental relacionando-o com o cotidiano desses alunos seguindo as recomendações dos Parâmetros Curriculares Nacionais do Ensino Fundamental em trabalhar de forma contextualizada, possibilitando ao aluno refletir sobre a natureza do conhecimento e do fazer científico e tecnológico [6].

A pesquisa desenvolvida utilizou uma abordagem do tipo quali-quantitativa e foi aplicada em uma escola da Rede Pública Municipal de Ensino no Município de São Miguel do Guamá, localizada no Estado do Pará.

O público alvo da pesquisa foi composto por uma turma da EJA da quarta etapa do ensino fundamental, do terceiro turno. A amostra era composta por 20 jovens no primeiro dia de intervenção e por 14 jovens no segundo dia nas faixas etárias de 15 a 39 anos de idade.

No primeiro dia de intervenção foi aplicado um questionário inicial de sondagem contendo sete questões abertas e fechadas, referentes a percepção desses alunos em relação à disciplina química e também sobre a utilização de atividades experimentais nas aulas de química. Esta análise foi realizada tendo em vista verificar o que os alunos acham da disciplina química e também se o professor costuma utilizar experimentos nas suas aulas.

No segundo dia com a ajuda de um projetor multimídia, foi ministrada uma aula teórica contextualizada, relacionando-a com a vivência e o conhecimento desses alunos ao longo da vida deles, com a história e evolução dos modelos atômicos. Esta aula teve como objetivo mostrar os diferentes modelos atômicos, bem como a contribuição cientifica de seus formuladores no decorrer da história. A aula ainda buscou chamar a atenção dos alunos para que eles percebessem a importância da evolução desses modelos para o desenvolvimento científico atual. Ao término desta aula teórica foi realizado um experimento baseado no salto quântico proposto no modelo atômico de Niels Bohr. Esta atividade experimental foi realizada na própria sala de aula com alguns reagentes químicos e matérias utilizados no cotidiano desses alunos. O experimento realizado foi o teste da chama, onde adaptou-se a chama com uma lamparina a álcool. 
Ao final da atividade experimental aplicou-se outro questionário contendo cinco perguntas, entre abertas e fechadas, para verificar se através da aula experimental houve uma melhor absorção do conteúdo visto e, consequentemente uma melhor aprendizagem. A aplicação deste trabalho foi realizada no mês de Outubro de 2015.

\section{RESULTADOS E DISCUSSÃO}

\section{Análise do questionário inicial}

Analisando as respostas dadas pelos alunos para a primeira pergunta do questionário aplicado na primeira intervenção, pode-se notar que a maior parte dos alunos encontram dificuldades de aprendizagem nas aulas de química, que pode ser comprovado, pois, 70\% dos alunos apresentam algum tipo de dificuldade na disciplina em questão. Segundo Silva [7], muitos alunos sentem dificuldades para entender a disciplina de química, principalmente quando envolve cálculos, deste modo caracterizando-se como uma disciplina de difícil compreensão e odiada pela maioria dos alunos.

Devido à disciplina de química ser considerada uma matéria exata, a metodologia e a linguagem que o professor emprega em suas aulas é de fundamental importância para o processo de ensino-aprendizagem, pois de acordo com esses fatores o aluno pode ou não apresentar dificuldades nas aulas de química. Assim, a questão 02 perguntava "Quais as dificuldades encontradas nas aulas de Química?". Conforme as respostas dadas pelos alunos pode-se notar que as dificuldades dos alunos estão principalmente nos cálculos e na linguagem do professor, isso pode ser observado em algumas respostas dadas por eles:

\section{Aluno 01 "A professora tem a fala muito rebuscada". \\ Aluno 02 "São nas horas de cálculo que tenho dificuldades".}

De acordo com Silva [7], os alunos apresentam dificuldades em química em decorrência dos cálculos e a metodologia que o professor emprega em suas aulas.

Alguns alunos relataram que não possuem dificuldades em química. Como pode ser percebido na resposta do aluno 03 .

\section{Aluno 03 "Não tenho dificuldades nenhuma em química".}

Além do mais os alunos da modalidade EJA são considerados por um lado grupos homogêneos, pois apresentam dificuldade em determinada área e competência em outra, e heterogêneos por serem pessoas com diferentes habilidades e culturas de vida, fazendo com que $o$ papel do educador se torne cada vez mais difícil, já que, ele deve considerar a história de vida de cada educando no processo de ensino.

De acordo com a pergunta 03 do questionário, $70 \%$ dos alunos pesquisados consideram a disciplina química difícil e apenas $30 \%$ acham fácil. Conforme a química é apresentada para os alunos, ela pode se tornar uma disciplina de fácil ou difícil compreensão. Isso varia de acordo com a metodologia que o professor vai utilizar em suas aulas, porém como a maioria dos professores evidencia somente os cálculos ela acaba se tornando difícil para a maioria dos alunos. Assim, Santos et al. [8] afirma que devido à ênfase excessiva dos cálculos matemáticos dada pelos professores no ensino de química a mesma acaba se tornando uma disciplina de difícil compreensão.

A metodologia que o professor utiliza influencia diretamente no ensino-aprendizagem dos alunos, por isso a mesma é de suma importância para o entendimento da disciplina. Assim a questão 04 questionava “A que você atribui a difícil compreensão da disciplina química?”. Os resultados mostram que os alunos atribuem a difícil compreensão da disciplina à maneira como o professor explica o assunto não favorecendo a aprendizagem dos conteúdos abordados. Assim pode ser observado em algumas respostas dos alunos:

$$
\begin{aligned}
& \text { Aluno } 04 \text { "Quando o professor explica 'mau' e não repete a } \\
& \text { explicação". }
\end{aligned}
$$


Aluno 05 'Quando o professor só fala 'o' não 'faça' o nem uma experiência em sala de aula".

Aluno 06 "O modo que o professor ensina sem ter objetos que represente a química".

Os alunos da EJA trazem consigo saberes do seu cotidiano, eles querem ver na prática o que foi aplicado na teoria. Como relata o Aluno 5 e o Aluno 6 os professores aplicam apenas a teoria e não utilizam de atividades experimentais em sala e de objetos que representem a química durante as aulas, dificultando assim a compreensão da disciplina. $\mathrm{O}$ ensino tradicional atrelado a metodologias descontextualizadas, que dão ênfase apenas a teoria e ao estudo conceitual não favorecem a aprendizagem dos alunos. Quando o aluno assume no processo educacional apenas o papel de ouvinte a aprendizagem não acontece, e o conteúdo ministrado pelo professor é esquecido rapidamente [9].

A questão 05 pergunta "Quais medidas devem ser tomadas para que a disciplina de Química torne-se de fácil compreensão". Através das respostas dos alunos, a maioria disse que o professor deveria trazer para a sala de aula atividades experimentais para que eles pudessem observar na prática o que é química. Assim pode ser observado na resposta dada por um aluno.

Aluno 07 "trazer para sala de aula objetos que represente o que é química”.

Quando o professor trabalha em sala de aula atividades experimentais o aluno fica mais motivado a aprender e também ocorre uma melhor aprendizagem, pois ele estará relacionando a teoria com a prática. De acordo com Hoering et al. (2004) [11] quando o aluno observa o concreto, ocorre o desenvolvimento do raciocínio e o entendimento do assunto, e através da observação real do assunto pode construir conceito e não apenas imaginá-los

Relacionado a essa mesma questão com a resposta dada pelo Aluno 08, o mesmo em seu relato se considera culpado pelo insucesso na disciplina de química.

\section{Aluno 08 "Bem, eu acho que o problema está comigo, pois passei muito} tempo sem estudar".

Podemos observar através do relato do Aluno 08 que o mesmo atribui a si às dificuldades na aprendizagem de química devido aos longos anos longe do ambiente escolar, o que demonstra uma baixa autoestima desse personagem no sistema educacional.

No processo de ensino aprendizagem a pré-disposição em aprender é um requisito fundamental para uma aprendizagem eficaz, assim quando o professor selecionar o conteúdo, deve considerar as características dos alunos e buscar metodologias alternativas para torna-las significativas [8].

Segundo o estudo realizado por Pelizzari et al. [10] sobre a teoria de aprendizagem significativa proposta por Ausubel a aprendizagem é muito mais significativa quando se faz uma ligação entre os conhecimentos prévios que esses estudantes possuem com aquilo que ele precisa saber.

Outra resposta dada por um aluno quando disse que não acha a química difícil.

Aluno 09 'na verdade a disciplina 'e' muito fácil 'e' só os alunos que não prestam atenção nas aulas".

Com base na resposta do Aluno 09 verificamos o desinteresse nas aulas de química observada pela falta de atenção da maioria dos alunos durantes as aulas. Isso ocorre devido ao ensino tradicional imposto a eles, acarretando no desinteresse e na falta de motivação no processo de ensino aprendizagem. O aluno da EJA vem de uma jornada diária cansativa e ao entrar no ambiente escolar, o cansaço somado as aulas monótonas os levam ao desestímulo, deste modo, a escola tem a função de estimular o indivíduo a agir e interessar-se pela aprendizagem, despertando assim a motivação existente dentro de si [12]. 
Referente à questão 06 foi perguntado "O que seria uma aula prática experimental". A maioria dos alunos responderam que seria fazer experiência em sala de aula. Abaixo algumas respostas dadas pelos alunos.

\section{Aluno 10 "é poder tocar e botar em prática a atividade". \\ Aluno 11 "Uma aula que a gente faça experiências na sala". \\ Aluno 12 "não sei nunca tive".}

No relato do Aluno 10 e do Aluno 11 podemos observar que os entrevistados de uma forma bem simples souberam explicar sobre o que seria uma aula prática experimental, porém é possível perceber através da resposta do Aluno 12 que o mesmo por nunca ter tido uma prática experimental não soube responder. Isso demonstra que durante sua vida escolar o mesmo nunca participou deste tipo de atividade.

A falta de laboratórios, equipamentos especializados, tempo para organizar as aulas, falta de técnicos de laboratório entre outros, são os principais motivos que levam a não execução das atividades experimentais durante as aulas de química. Esses fatores não justificam a ausência desse tipo de atividade durante as aulas de química, pois muitas práticas experimentais não dependem do ambiente laboratorial e sim da disponibilidade do professor em planejar e organizar aulas que possibilitem ao aluno a participação mesmo na sala de aula. Isso por que não são necessários equipamentos sofisticados para a realização desse tipo de atividade, além do mais o professor conforme a realidade do seu ambiente poderá realizar adaptações que possibilitem a efetivação de práticas experimentais, utilizando materiais de baixo custo [13].

A questão 07 questionava o seguinte "Durante a sua vida escolar você já participou de uma aula prática experimental?". Das respostas dadas pelos alunos, 85\% dos pesquisados responderam que nunca tiveram aula experimental e apenas $15 \%$ já tiveram.

Os dados da questão 07 vêm reafirmar a resposta do aluno 12 da questão 06, onde $85 \%$ dos alunos pesquisados responderam que nunca participaram de uma aula prática experimental. Como podemos observar são diversos os fatores apontados como responsáveis pela ausência de atividades experimentais durante as aulas de Química, porém o professor bem capacitado ao exercício da profissão consegue superar as dificuldades encontradas no ambiente escolar e desenvolver habilidades que favoreçam a aplicação das aulas experimentais e deste modo contribuindo para a aprendizagem de seus alunos [14].

\section{Análise do questionário após atividade experimental}

Após a aula teórica e prática, foi aplicado um segundo questionário. A primeira questão perguntava "A aula experimental realizada foi de fácil entendimento?". Todos os alunos assinalaram que "Sim". Isso mostra que através do experimento que foi realizado os alunos conseguiram assimilar o conteúdo. Além do mais as aulas contextualizadas contribuem para uma melhor assimilação do conteúdo, possibilitando aos alunos atribuir significados do conhecimento do mundo a sua volta, bem como criar condições para que os mesmos despertem em si a curiosidade e a satisfação em construir seu próprio conhecimento e visão do mundo [15]. A forma com que o professor ensina influencia diretamente na aceitação do aluno enquanto a construção do conhecimento [16].

A experimentação chama atenção dos alunos por ser algo diferente do monotonismo das aulas tradicionais. Assim sendo, na questão 02 foi perguntado "O que mais lhe chamou a atenção no experimento realizado?".

\section{Aluno 01 "A simplicidade de 'como o' se explica". \\ Aluno 02 "foi quando eles botaram as coisas da química". \\ Aluno 03 "foi a mudança de cores de acordo com os elementos utilizados na prática".}

Com as respostas de alguns alunos, referente à questão 02 percebe-se que a prática trabalhada despertou a atenção desses, onde os mesmos puderam observar a "química" facilitando a 
aprendizagem por parte desses alunos. Giordan [17] afirma que a experimentação desperta um forte interesse dos alunos facilitando-o a compreensão dos assuntos vistos em sala de aula, não importa a idade.

A teoria e a prática devem atuar em conjunto no processo de ensino aprendizagem para que ocorra de fato assimilação dos conteúdos. Assim sendo, na questão 03 foi perguntado "A aula experimental teve alguma relação com a aula expositiva?". Dentre todos os alunos presentes $100 \%$ assinalaram que "Sim". Com isso pode-se observa que os discentes conseguiram relacionar a parte teórica com a prática.

Assim, Silveiro [18] fala que experimentação contribui diretamente para aprendizagem dos alunos, pois ela esclarece muitas dúvidas pendentes na teoria e através da aula prática o aluno compreende melhor o assunto, quanto mais integrada for a teoria e prática, mais a aprendizagem se torna significativa.

Quando a prática experimental é bem planejada favorece a assimilação dos conteúdos abordados. A questão 04 questionava "Em sua opinião houve compreensão do assunto abordado? Por quê??".

Aluno 04 "sim porque o que eles explicaram nos vimos ser realizados".

Aluno 05 "houve sim porque eu entendi melhor do que escrevendo".

Aluno 06 "Sim, porque como a gente viu na prática foi bem interessante".

As respostas dadas pelos alunos referente à questão 04 foram unânimes, todos responderam que conseguiram assimilar o conteúdo trabalhado, assim como observado em algumas respostas acima. Isso mostra que a atividade prática realizada foi de fácil entendimento e que a experimentação contribuiu diretamente para o processo de ensino-aprendizagem desses alunos.

Isso mostra que a experimentação tem um papel fundamental no processo de ensino aprendizagem, uma vez que por meio dela novos caminhos de aprendizagem são abertos, além do mais a experimentação permite a contextualização e o estímulo de questionamentos de investigação [19].

A utilização da experimentação contribuiu de forma significativa no processo de ensinoaprendizagem desses alunos. Deste modo a questão 05 perguntava "A prática experimental contribuiu para um melhor entendimento do conteúdo?".

\section{Aluno 07 "Sim porque eu fiquei prestando atenção". \\ Aluno 08 "sim porque nós vimos o que é química na prática". \\ Aluno 09 "Sim porque deu pra ver ao vivo".}

Fazendo uma análise das respostas desses alunos percebe-se que a atividade experimental fez com que os alunos ficassem mais atentos na aula, e puderam ver a química "ao vivo", fato que pode ser comprovado pelas respostas transcritas acima, deste modo, pode-se dizer que esses alunos tiveram uma aprendizagem referente ao assunto visto e poderão aplicar esses novos conhecimentos obtidos em seu cotidiano. Neto [3] diz que o professor não tem que aplicar somente fórmulas e teorias, e sim deve ajudar os seus alunos para que de uma forma ele possa aplicar os conhecimentos químicos na sociedade.

Também podemos constatar através das respostas obtidas na questão 05 que a prática experimental contribuiu para uma melhor assimilação do conteúdo aplicado de forma teórica, deste modo, as atividades experimentais utilizadas como práticas metodológicas na EJA proporcionou a motivação dos alunos desta modalidade, tornando-se uma ferramenta essencial no processo de ensino aprendizagem. Os assuntos químicos quando contextualizados e relacionados com o cotidiano do aluno despertam o interesse, a participação e motivação dos mesmos na aquisição do conhecimento [20]. 


\section{CONCLUSÃO}

Com base nos resultados obtidos pode-se perceber que a utilização de aulas práticas experimentais no âmbito escolar é uma alternativa válida e muito importante para o ensino de química apresentando resultados bastante satisfatórios para a motivação dos alunos, pois eles podem aprender com maior facilidade o assunto ministrado, bem como foi possível observar uma maior participação dos alunos na aula tornando assim um ensino mais eficaz, participativo e integrador.

Os alunos da EJA apresentam diferentes características como a baixa autoestima e a falta de motivação, deste modo devem ser estimulados a tornar-se um ser ativo no processo de ensino, assim aulas práticas aplicadas com o intuito de envolver os alunos contribuíram para o melhor entendimento do assunto visto, bem como promoveu o envolvimento e participação dos mesmos no processo de aprendizagem.

Assim conciliar as aulas teóricas juntamente com as aulas práticas possibilita ao aluno uma melhor compreensão dos assuntos ministrados além de permitir também um ensino contextualizado. Porém é necessário salientar que a teoria e prática tem que atuar em conjunto para que assim de fato ocorra a assimilação do conteúdo.

Portanto a utilização de experimentos nas aulas de química como prática metodológica deixa o caminho do ensino tradicional e traça um novo rumo na educação que atende os Parâmetros Curriculares Nacionais de trabalhar os assuntos de modo contextualizado, além de contribuir para que as aulas de química se tornem de fácil compreensão, mas deve ficar claro que o papel da experimentação no ensino é abrir novos caminhos de aprendizagem buscando sempre acrescentar algo no conhecimento dos alunos e não apenas ser uma ferramenta para deixar a aula diferente.

\section{AGRADECIMENTOS}

Ao Centro de Ciências Sociais e Educação da Universidade do Estado do Pará localizado em Belém-PA e a escola da rede municipal de ensino de São Miguel do Guamá, Pará onde a pesquisa foi desenvolvida.

\section{REFERÊNCIAS BIBLIOGRÁFICAS}

1. Brasil. Constituição da República Federativa do Brasil: texto constitucional promulgado em 5 de outubro de 1988, com as alterações adotadas pelas Emendas Constitucionais nos 1/1992 a 68/2011, pelo Decreto Legislativo $n^{\circ}$ 186/2008 e pelas Emendas Constitucionais de Revisão nos 1 a 6/1994. - 35. ed. Brasília: Câmara dos Deputados, Edições Câmara, 2012.

2. Nascimento RL. O ensino de química na modalidade educação de jovens e adultos e o cotidiano como estratégia de ensino/aprendizagem. 2012. 32 f. Trabalho de Conclusão de Curso. Faculdade Integrada da Grande Fortaleza - FGT. Peabiru - Paraná. 2012.

3. Neto JJAG. Preparo de produtos domissanitários como alternativa para o ensino de química de jovens e adultos (EJA). 2011. 47 f. Trabalho de Conclusão de Curso. Universidade Estadual de Goiás - UEG. Anápolis - Goiás. 2011.

4. Rosa MF, Silva OS, Galvan FB. Ciência Forense no Ensino de Química por Meio da Experimentação. Química Nova na Escola. 2013 abr; 1-9.

5. Santos TNT, Freitas LM. Aulas práticas no ensino de ciências para educação de jovens e adultos. UFPA, Bragança, p.01-03, 2013. Disponível em: < http://santoangelo.uri.br/erebiosul2013/anais/wpcontent/uploads/2013/07/poster/13409_79_Tatiane_Nazareth_Trindade_dos_Santos.pdf >. Acesso em: 12 de Ago. 2015.

6. Brasil. Secretaria de Educação Fundamental. Parâmetros Curriculares Nacionais: Ciências Naturais / Secretaria de Educação Fundamental. - Brasília: MEC / SEF, 1998. 138p. 
7. Silva GS. A abordagem do modelo atômico de Bohr através de atividades experimentais e de modelagem. 2013. 217 f. Dissertação de Mestrado. Universidade Federal de Santa Maria - UFSM. Santa Maria - RS. 2013.

8. Santos AO, Silva RP, Andrade D, Lima JPM. Dificuldades e Motivações de Aprendizagem em Química de Alunos do Ensino Médio Investigadas em Ações do (PIBID/UFS/Química). Scientia Plena. 2013; 9 (7): 077204.

9. Lira LS. A Importância da Prática Experimental no Ensino de Biologia na Educação de Jovens e Adultos. 2013. 65 f. Trabalho de Conclusão do Curso de Licenciatura em Ciências Biológicas. João Pessoa, Paraíba, 2013.

10. Pelizzari A, Kriegl ML, Baron MP, Finck NTL, Dorocinski SI. Teoria da Aprendizagem Significativa Segundo Ausubel. Revista PEC. 2002; 1: 37-42.

11. Hoernig AM, Pereira AB. As aulas de Ciências Iniciando pela Prática: O que Pensam os Alunos. Revista da Associação Brasileira de Pesquisa em Educação em Ciências. 2004; 4(3):19-28.

12. Soares MAF. Perfil do Aluno da Eja / Médio na Escola Dr. Alfredo Pessoa de Lima. 2007. 58 f. Monografia Apresentada para Obtenção do Grau de Especialista. Universidade Federal da Paraíba. Bananeira, Paraiba, 2007.

13. Berezuk PA, Inada P. Avaliação dos Laboratórios de Ciências e Biologia das Escolas Públicas de Maringá, Estado do Paraná. Acta Scientiarum. Human and Social Sciences. 2010; 32(2): 207-215.

14. Silva FSS, Morais L.JO, Cunha, IPR. Dificuldades dos Professores de Biologia em Ministrar Aulas Práticas em Escolas Públicas e Privadas do Município de Imperatriz (MA). Revista UNI. 2011; 1(1): 135-149.

15. Wartha EJ, Alário AF. A Contextualização no Ensino de Química Através do Livro Didático. Química Nova na Escola. 2005; 22: 42-47.

16. Galiazzi MC, Gonçalves FP. A Natureza Pedagógica da Experimentação: Uma Pesquisa na Licenciatura em Química. Química Nova. 2004; 27(2): 326-331.

17. Giordan M. O Papel da Experimentação no Ensino de Ciências. Química Nova na Escola. 1999; 10: 4349.

18. Silvério J. Atividades experimentais em sala de aula para o ensino da química: percepção dos alunos e professor. 2012. 50 f. Trabalho de Conclusão de Curso (Licenciatura em Química), Universidade Tecnológica Federal do Paraná, Pato Branco, 2012.

19. Guimarães CC. Experimentação no Ensino de Química: Caminhos e Descaminhos Rumo à Aprendizagem Significativa. Química Nova na Escola. 2009; 31(3): 198-202.

20. Assis MS. Experimentação como Estratégia Didática para o Ensino de Química na Educação de Jovens e Adultos. Trabalho de Conclusão de Curso. Universidade Federal do Rio Grande do Sul - Instituto de Química. 2011.29 f. Porto Alegre - RS. 2011. 